Компаративні досліАження слов'янських мов і Аітератур. 2020. Випуск 36

Палій М.

к.ф.н., дои., Шуменський університет імені Спископа Константина Преславського (Республіка Болгарія)

Paliy M.

PhD, Assoc. Prof., Konstantin Preslavski University Shumen (Republic of

Bulgaria)

\author{
КОНСПЕКТЬТ КАТО МЕТОДИЧЕСКИ ПОХВАТ ЗА \\ ОСМИСЛЯНЕ И РЕПРОДУЦИРАНЕ НА ТЕКСТОВЕ ПО \\ СПЕЦИАЛИЗИРАНИТЕ ДИСЦИПЛИНИ ПРИ ОБУЧЕНИЕ НА \\ ЧУЖДЕСТРАННИ СТУДЕНТИ
}

\title{
NOTE-TAKING AS A METHODOLOGICAL TECHNIQUE FOR RATIONALIZATION AND REPRODUCTION OF SPECIALIZED TEXTS IN FOREIGN STUDENTS' EDUCATION
}

Стаття присвячується конспектуванню як одному із важливих аспектів у навчанні іноземних студентів болгарській мові. Розглядаються окремі питання, пов 'язані зі специффікою такого навчання у технічному вищому навчальному закладі. Описано етапи формування навичок конспектування на лекиіях та під час опрацюювання фахової літератури зі спеціалізованих предметів. Для вирішення иієї проблеми пропонуються конкретні методичні ідеї.

Ключові слова: технічний вищий навчальний заклад, навчання іноземних студентів, методика навчання болгарській мові, конспектування, спеціалізована лексика.

The paper presents one of the most important moments in foreign language teaching and learning taking into accounts the relevance of the European language policy and the importance of foreign languages in education. Habit formation of taking notes on lectures and specialized subject literature is one of the primary tasks in teaching and training in a technical school. Questions concerning methodologically correct organization of note-taking learning process, increasing the level of listening habits for further successful involvement of foreign 
language students in the complete learning process, require attention and development of specialized training models, which can support students' better perception of greater amount of audio materials, seminars, lectures, practical classes, etc. Particular attention should be paid to the deliberate, purposeful and well-organized students' independent work, which promotes the acquisition of habits. Autonomous learning requires responsible attitude and becomes an effective tool for shaping their professional competence.

The author considers some aspects concerning the peculiarities of foreign language teaching to overseas students in a polytechnic university. Described are the stages of developing the skills for note-taking during lectures and during reading reference books on specialized disciplines. The author suggests methodological ideas for solving this language problem.

Key words: polytechnic university, обучение на foreign students, methodology for teaching Bulgarian language, note-taking, specialized vocabulary.

Приобщаването на българската образователна система към нормите на европейското образование предполага непрекъсната обмяна на идеи, практики и движение на студенти и преподаватели. Този процес изисква от академичната общност сериозни усилия за постигане на устойчиво качество на висшето образование в условията на динамични социални и икономически промени.

Обучението на чуждестранни студенти е особено важно, като се има предвид актуалността на така наречената езикова политика или езиците в образованието. В това понятие включваме не само изучаването на чужди езици, но също така и преподаването на специализирано учебно съдържание на един или повече езици. [Stoicheva 2006: 33]. В голяма степен това се отнася и за преподаването на български език като чужд. Той става все по-популярен в Европа, което е свързано с интереса й към България и европейските перспективи на страната.

Според разработената от Съвета за Европа „Обща европейска езикова рамка“ чуждоезиковото обучение има политическо, социално и културно значение и е в унисон с целите на Съвета на Европа. Проблемите на глобализация засягат пряко чуждоезиковото обучение и насърчават многообразието от форми на езиковата подготовка. Във връзка с това 
чуждоезиковото обучение заема ключово място и в модерните учебни програми, предназначени за специализирано техническо обучение. В съответствие с гореизложеното проблемът за качеството и методите на такова специфично обучение е особено актуален. На тази потребност отговаря и въвеждането на Европейския езиков пакет, официално признат от Съвета на Европа и предназначен да стимулира многоезичието в съвременна Европа [Palii 2004: 71].

Модернизирането на образователната система предполага образование от най-високо качество, което се основава на използване на актуални методи в обучението по чужд език, съвременни материали и модерно оборудване. Търсенето на най-ефективни методи при подготовката по български език на чуждестранни студенти за практическа комуникативна дейност е една от главните задачи на специализираното висше училище. Методиката на обученито по български език стриктно следва стандартите и модерните тенденции в чуждоезиковото обучение.

Обучението по български език (по-нататък ОБЕ) в техническо училище е подчинено на необходимостта чуждестранните студенти да придобиват лингвистична, комуникативно-речева и обща култура, което им дава възможност да развият усета си за правилно устно и писмено изразяване според езиковите норми на българския език. Но основните задачи при обучение по чужд език в техническо училище са не само усвояването на произносителните, правоговорните, правописните и граматичните умения и навици от обучаваните, но и постепенното обогатяване и активизиране на техния речник в съответствие с нуждите на езиковата им практика и професионалната им реализация. Постигането на тези важни задачи е възможно с помощта на програмирани методи, комуникативноиндивидуален подход и цялостни модели на обучението по чужд език. [Palii 2007]. Въпросите, свързани с обучението на чуждестранните студенти да конспектират, особено на етапа на предварителната подготовка на изучаването на български език, в света на комуникативната методика се считат за доста важни. На този проблем са посветени доста научни трудове: Авдеева 2005; Васильева 2005; Димитрова 2015, Славова 1999, 
Константинова 2003, Елухина 1991; Кочкина 2007; Brown, Yule 1983; Ur 1984 и др. В тези изследвания се разглеждат въпроси за методически правилна организация на процеса на обучение за конспектиране, за повишаване нивото на навици за аудиране с цел успешно по-нататъшно включване на чуждестранните студенти в пълноценния учебен процес. Разработват се специализирани модели за обучение, подпомагащи възприемането на по-голям обем аудиоматериали, семинари, лекции, практически занятия и др.

В дадената статия се опитахме да споделим някои наши виждания относно разглеждания проблем.

След завършване на подготвителен курс, където се изучава само разговорен език, чуждестранните студенти преминават в I курс. Там те се сбльскват с трудностите на езиковата бариера, тъй като не са запознати с техническата лексика. Чуждестранните студенти заедно с българските слушат лекции по различни дисциплини, което е основен източник за информация; запознават се също така и със специализираната и научна литература (учебни помагала, доклади, статии и т.н.). Това е необходимата информация, нуждаеща се от преработване с помощта на конспектиране, което за чуждестранните студенти на този етап е доста сложно. А изискванията към всички студенти (и български, и чуждестранни) са еднакви. Практиката показва, че в първи курс чуждестранните студенти изпитват големи трудности не само при разбирането на преподнасяния материал, но и във връзка с неумението им свободно и коректно да демонстрират на български език знанията си по специализираните дисциплини в изказвания на различно езиково ниво. Това налага по време на този етап на обучението да се обогатява речниковият запас на чуждестранните студенти с повече термини от съответната специалност и да се дава информация за граматически правилно построяване на изречението. Тук е важна ролята на преподавателя по български език, който е задължен така да поднесе езиковия материал, че всяко явление да бъде усвоено на всички езикови равнища (фонетично, лексично, граматично, контекстуално-ситуативно). Едно от най-важните условия за 
успешно обучение по български език на чуждестранните студенти в техническо висше училище е взаимосвързаното развитие на умения и навици в усната и писмена реч и компонентите им.

Конспектирането (от лат. cons pectus - обзор, очерк), както е известно, е кратко, последователно писмено изложение на съдържанието на статия, учебник или лекция, включващо основните положения на прочетеното или чутото. Ако конспектът е направен добре, лесно може да бъде възпроизведено съдържанието на целия материал. Основните принципи на конспекта са краткост, логика, последователност, лесно възприемане.

За успешно конспектиране както на писмен, така и на устен първоизточник, са необходими умения за адекватно възприемане на информацията, за отделяне на основната и второстепенната информация, за трансформиране, за съкращаване, където е необходимо, за търсене на опорни думи, а също така и за фиксиране, т.е. кратко записване на информацията. На всичко това чуждестранният студент трябва да бъде научен от преподавателя си по български език. Но това е доста дълъг и труден процес. Трудностите са предизвикани също така и от известния факт, че когато студентите конспектират устната реч на преподавателя, около 80-90\% на вниманието им се отделя за преработване на информацията и оформяне на текста и само около 10-15\% - за разбиране на чутото. Това се дължи основно на това, че новата техническа терминология, както споменахме по-горе, е почти непозната на чуждестранните студенти.

И така, конспектирането по време на лекции, чрез което се маркират основните моменти, както и конспектирането на текстове от чуждестранните студенти, е един от важните моменти при обучението в специализирано училище. Необходимостта от такова обучение произтича от следното:

•чуждестранните студенти след подготвителен курс трудно възприемат слухово българската реч в нормалното темпо на лекцията.

•трудно записват първите лекции дори на родния си език, а още повече се затрудняват при записване на български. 
Във връзка с това най-ефективната помощ, която чуждестранните студенти могат да получат в часовете по български език, се състои не само в усвояването на по-голям брой адаптирани текстове, а и в овладяването на граматичните норми на научния стил, специализираната лексика и терминология в такава степен, че да могат да възприемат слухово и да конспектират лекциите, а също и успешно да ползват учебната и научна литература. В противен случай те няма да могат активно да участват в учебния процес. Опитьт на преподавателя по български език да адаптира лекциите по специалността с оглед на възможностите на чуждестранните студенти да възприемат информация на български език понижава изискванията и е предпоставка за повърхностно изучаване на отделни теми.

От особена важност е подборът на текстовете. Те трябва да са съобразени със средата, в която ще се изпозват - дидактически дискурс, с неговите образователни и възпитателни параметри. На второ място, текстът винаги е обвързан с определен социален контекст, който носи белезите на социокултурните сфери на общуване и се проявява във функционалностиловата характеристика на текста. [Dimitrova 2015: 183]. Основният текст е изходна точка за обучение, формиращо умения за:

•конспектиране, чрез което се маркират основните моменти;

-съставяне на план;

•конспектиране на текстове по специализираните дисциплини.

Всичко това съдържа главните тези на изучаваната тема. По време на работа върху основния текст е добре да бъдат използвани допълнителни текстове, отначало адаптирани, след това взети от учебника по специалността, но вече без промени, и на последен етап - текстове, представляващи научни статии и трудове, които са препорьчани от специализираните катедри. Допълнителните текстове, които се изучават на база основен текст, спомагат за затвърдяване на знанията по български език, развиват говорните и писмени навици на студентите и попълват речниковия им състав.

Формирането на навици за водене на конспект върху лекциите и литературата по специализираните предмети трябва да започне още от 
първите часове по български език, тъй като на преподавателя му предстои да научи студентите в минимално кратък срок да отделят от четения или слушания текст основните положения и да ги записват, като използват вече усвоената лексика и научените граматични форми и конструкции.

Независимо от това, че в обучението все повече навлизат съвременните технически средства и в повечето случаи студентите идват в часовете с лаптопи и таблети, конспектирането си остава важна част от ОБЕ. Воденето на конспект е сложна задача за чуждестранните студенти, тъй като те трябва да умеят да разграничават същественото в информацията и да го отразят правилно, т.е. трябва да разбират съдържанието на текста. Затова преподавателят може да предложи на студентите кратко да запишат съдържанието на вече научения от тях текст, като съставят план и стриктно се придържат към него. Планът, т.е последователното представяне на отделните части на съдържанието в кратки формулировки, отразяващи темата или основната мисъл, е основата на конспекта. Съставянето на подробен план подпомага за по-дълбоко осъзнаване основните положения на темата и тяхната взаимовръзка, за отделяне на главното от второстепенното и служи за сериозна опора в придобиването на умения и навици за смислен преразказ и строга научна последователност при писане на контролни, курсови работи и доклади.

Задачата на преподавателя е да следи в изложението да се спазва строга последователност и то да отговаря на изискванията за правилно лексикално и граматично оформяне. Важен е моментът студентите да разграничават конспектирането от буквалното преписване на текста.

Методиката на това обучение в значителна степен зависи от нивото на развитие на чуждестранните студенти, от това, колко те са запознати с правилата за съставяне на план. Докато не бъде проведена съответната лексикална и граматична работа и не бъдат усвоени всички непознати думи от текста, а също и употребените в него форми и конструкции, не трябва да се пристъпва към съставянето на план. Добре е текстът да бъде разделен на части, а задачата на студентите е да озаглавят всяка от тях. Към всяка точка от плана обучаващите се трябва да могат да дадат 
малък коментар. Ако, според нивото на техните знания, те още не са готови за изпълнение на такъв вид задача, необходимо е да се проведе допълнителна работа. След прочитането на определен откъс на текста студентът се опитва да преразкаже получената информация с едно-две кратки изречения, а преподавателят предлага на другите студенти да формулират своите отговори. Всички отговори се сравняват по пълнота на съдържанието, съответствие с прочетеното и краткост на изложението, след което се преминава към формулиране на първата точка от плана. В процеса на изучаване на специализираните текстове студентите работят върху съставяне на плана, използвайки голяма част от изучения граматичен материал.

За усвояване на специализираната информация ефективно е по всяка точка на плана, където вече присъстват определени коментарии, да се вписват и използват термини, имащи водещо значение и отразяващи основните тези на изучаваната тема. Така текстьт, съставен вече от студента, се обогатява с допьлнителен материал. Задачата на преподавателя е да контролира, дали обучаващите са коректни в отговорите си. Отделно се записват непознатите думи, без които не може да бъде направен преразказът на текста с необходимата познавателна информация. Студентите трябва да направят опит да разкажат текста със свои думи, като използват новата терминология, записана на дъската. Ако обучаващите се затрудняват при преразказ на общото съдържание на текста, преподавателят има възможност да подскаже необходимата дума като я тълкува или подбере синоним. Но това не важи за термините, които студентите са задължени да използват точно и коректно, като не се съмняват в значението на всеки от тях. При такъв вид работа максимално се активизира не само индивидуалният запас от общоупотребима лексика, но се попълва и терминологичният речник по специализираните дисциплини.

Допълнителните текстове, подбрани от преподавателя, трябва да включват нови думи и словосъчетания, които ще бъдат необходими не само за преразказ на съдьржанието, но ще се употребяват и в следващи текстове 
и упражнения. Тук задължително се включва и трудната лексика от основния текст. Такива текстове също дават възможност за повтаряне на изучаваните граматични форми и конструкции, което спомага за тяхното затвърдяване и практическо усвояване на новата лексикална основа. [Slavova 1999]. В допълнителните текстове трябва да фигурират и познати за чуждестранните студенти общоупотребими думи, като например: дърво, въглища, завод, камък, машини, стругове и други, които те могат лесно да използват при разказване на съдържанието на текста. За развиване на говорните им умения и активизиране на запаса от думи, а също и за проверка разбирането на допълнителния текст, преподавателят задава определени въпроси, които предоставят информация за степента на усвояване на четения или слушания текст.

Необходимо е също така студентите да се запознаят и с въвеждането на цитати при конспектиране на специализираните теми. За тях е необходимо да знаят, че цитатът или се записва буквално и се слага в кавички, или, ако е дълъг и лексически сложен, се преразказва.

Самостоятелното представяне на прочетения и преведен от чуждестранните студенти специализиран текст спомага за по-бързо усвояване на основните моменти, които са обект на конспектиране. В началото грешките носят общ характер и за чуждестранните студенти е пополезно да слушат речевото оформяне на едни и същи понятия и мисли. Необходимо е направеният от студента конспект да бъде проверен и от граматична, и от логическа гледна точка. Тук е важно, дали е правилно разположението на информацията във всяка точка на плана, коректно ли са използвани цитираните от студента мисли, правилно ли е подбрана новата лексика. Задължително е обсъждането на синтактичните конструкции на изреченията и употребата на граматичните форми. Студентите са длъжни да възпроизведат прочетеното, като използват познатата за тях лексика и да пишат изречения с добре познати, макар и по-елементарни, конструкции. Така че в началото е желателно студентите да бъдат научени да използват прости и най-често срещани видове сложни изречения, които са им 
известни още от подготвителен курс (с който, която, което, които; затова, че; за да и др.).

Успоредно с конспектирането на текстовете се провежда и обучението в слухово възприемане (аудиране) на лекционния материал по специализираните дисциплини. Чуждестранните студенти се учат да възприемат слухово различни варианти при изложението на една и съща научна тема, да оценяват избора на точните и пълни формулировки, както и да откриват граматични грешки. Един от етапите на обучението е прослушването на текста, но не с гласа на преподавателя-българист, а с гласа на преподавателя по специализираната дисциплина. След прослушването вече се прави конспект. Работата с касетофон или дисково устройства при обучението дава възможност за трениране на слуховото възприятие, активизира устното възпроизвеждане на прослушания материал-образец и засилва вниманието на обучаващите се. Благодарение на помощните средства чуждестранните студенти могат да бъдат научени да възприемат българската реч с различно темпо, различен маниер и различна специфика на четене. Необходимо е преподавателят по български език да развие у чуждестранните студенти „самостоятелност“ и „незвисимост“ на слуха, леко откъсната от непосредственото осмисляне на материала. Това ще им помогне да записват лекциите даже тогава, когато в тях има непознати думи и понятия, и ще ги подготви за решаването на първостепенната за тях задача: да възприемат информация по устен път и едновременно с това да конспектират, слушайки лекциите на преподавателите по специализираните дисциплини.

Последен етап в обучението на чуждестранните студенти да конспектират възприемания слухово материал е непосредственното автоматично записване на прослушаната информация. За тази цел се използва информацията, усвоена по време на часовете, която е разположена в строга последователност съобразно с плана на темата. А чуждестранните студенти са дльжни вече да умеят да конспектират основните положения в изложената тема. Необходимо е също да бъдат научени да записват 
съкратено информацията, използвайки съкращенията, употребявани в българския език ( $m-$ тон; др. - други; кг - килограм и т.н.).

Както вече отбелязахме, най-трудното за чуждестранните студенти, обучаващи се в техническо висше училище, е усвояването на специфичната терминология. Естествено е студентите да се стремят да използват термините, но, обикновено, недостатъчното познаване на лексиката по специализираните дисциплини и все още слабото знание на граматичните норми на българския език не им позволява лесно да предадат със свои думи научната информация от техническия текст. Задачата на преподавателя е да научи студентите да се ориентират в многообразието на непознатите думи и да се спират само на найважната информация, необходима за преразказ на дадена тема. Препорьките за обучаващите се са следните: внимателно слушайте, какво говори лекторьт, обрьщайте внимание на интонацията, понижаването или повишаването на гласа, паузите. Паузите показват края на едната част и началото на другата; не е необходимо да се записва абсолютно всичко - трябва да се записва само най-главното [Zherebtsova 2013: 255].

Bce по-сериозно място се отделя на целенасочената и добре организираната самостоятелна работа на студентите, която подпомага придобиването на навици, изисква отговорно отношение и се явява ефективно средство за формиране на тяхната професионална компетентност. „Самостоятелната работа позволява да се развива способността за интелектуален и физически труд, да се повишава ефективността на процеса на усвояване на системни знания и изграждането на умения за приложението им в практическата дейност" [Milkov, L. 2002: 397]. Тя трябва да е индивидуална и диференцирана, съобразно курса на студентите, техните възможности, интереси и изяви. Дори и по-големият хорариум български език за чуждестранните студенти не позволява, за съжаление, да бъде обхваната цялата тематика от специализираните дисциплини; не мальк обем от материала, необходим за научаване, остава за самостоятелна работа. Основната 
функция на преподавателя в този вид обучение е да осъществява системен и целенасочен контрол върху изпълнението на самостоятелната работа, да предприема мерки за повишаване на мотивацията на студентите и, разбира се, да поощрява качественото изпълнение на самостоятелната работа. Самостоятелната работа дава възможност на чуждестранните студенти постоянно да се развиват и да умеят да прилагат знанията си в различни ситуации и контекст, независимо от областта на професионалната си подготовка и реализация.

Конспектирането на основните моменти от слушаната лекция, както и конспектирането на специализирани текстове от чуждестранни студенти, като специфичен вид на обучение и методически похват, е много важно в техническото училище. Някои от предложените идеи могат да подпомогнат обучението в тази насока.

В изследваната проблематика се откроява редица нерешени и дискусионни проблеми, което поставя доста разнообразни въпроси относно ефективността на процеса на обучение. ОБЕ би могло да се осъществява чрез подобряване общата структура на учебния процес, усъвършенстване на методически похвати, активно използване на технически средства, икономичен и целесъобразен подбор на езиковия материал, не на последно място - обучение на водене на конспект. Важно значение има и подобряването на атмосферата при обучението, отчитане на физиологичните и психологическите особености на обучаващия и обучавания. Това са основните елементи на формите и методите на обучение при подготовка на един съвременен специалист, особено отчитайки спецификата на обучение на чуждестранните студенти.

\section{REFERENCES:}

1. Dimitrova D. (2015). Tekstat i negovia analiz. Komunikativnata kompetentnost $\mathrm{v}$ savremenniia nauchen diskurs. Sbornik v chest na 70-godishninata na prof. K.Dimchev. Sofiia, Bulvest 2000, pp.178-184.

2. Milkov L. (2002). Didaktika, IuniEkspres, Shumen, 500p.

2. Palii M. (2007). Teoretichni i prakticheski problemi na obuchenieto po balgarski ezik kato vtori ezik. (Za izuchavaneto na balgarski ezik ot chuzhdestranni studenti v 
tekhnicheski visshi uchilishcha. TU-Varna, Departament „Ezikovo obuchenie“, 160p.

3. Palii M., Karastateva. V (2004). Standartite v chuzhdoezikovoto obuchenie - sredstvo za uspeshna profesionalna realizaciia po patia kam evrointegraciiata. - Izvestiia na Saiuza na uchenite. Varna, seriia „Khumanitarni nauki“, pp.71-73.

4. Slavova L. (1999) Niakoi teoretichni aspekti na obuchenieto po balgarski ezik v chuzhdoezikova sreda. Tendencii v obuchenieto po balgarski ezik. - Sbornik v chest na 65-godishninata na prof. K.Dimchev. - Sofiia, Bulvest 2000, pp.45-48.

5. Stojcheva M. (2006) Evropeiska ezikova politika. Sofiia, Universitetsko izdatelstvo „Sv. Kliment Okhridski”, p.33.

6. Zherebtsova Zh. (2013). Model obucheniia inostrannikh studentov audirovaniiu i konspektirovaniiu. - Vestnik Tambovskogo gosudarstvennogo universiteta im.G.R. Derzhavina, Gumanitarnie nauki, vip.4 (120), p.255

Пахомова $\boldsymbol{C}$.

д.ф.н., проф., Пряшівський університет (Республіка Словаччина)

Pakhomova S.

Doctor Hab., Professor, University of Preshov (Republic of Slovakia)

\section{СЛОВАЦЬКА ТА УКРАЇНСЬКА ЛІНГВСТИЧНА ТЕРМІНОЛОГІЯ: СЕМАНТИЧНІ КОНТРАСТИ}

\section{SLOVAK AND UKRAINIAN LINGUISTIC TERMINOLOGY: SEMANTIC CONTRASTS}

Спостереження за використанням лінгвістичної термінологї в словацькій та українській навчальній $і$ науковій практиці дозволяє визначити численні факти асиметрії мовознавчих термінів у ракурсі їх змісту $i$ форми. Незбіги у внутрішньосемантичній структурі лінгвістичних термінів словацької та украӥнської мов створюють проблеми як для студентів, так $і$ для викладачів, особливо в білінгвальному середовищі або при викладанні словацької/української мови як іноземної. У статті представлено зіставне синхронічне дослідження словацьких та українських лінгвістичних термінів, які активно використовуються 